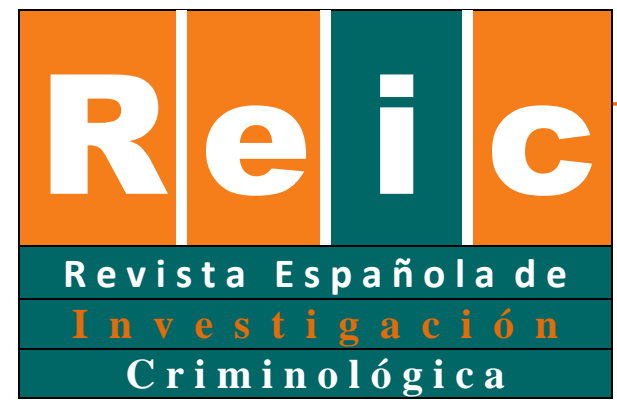

Villacampa \& Pujols

\title{
Prevalencia y dinámica de la victimización por stalking en población universitaria
}

\section{Prevalence and dynamics of stalking victimisation in university population}

Recibido el 29 noviembre 2016/Publicado el 4 julio 2017

Carolina Villacampa

Universidad de Lleida

Alejandra Pujols

Universidad de Lleida

\section{RESUMEN}

El stalking constituye un fenómeno que fue criminalizado en España en 2015. Los estudios sobre victimización por stalking realizados hasta el momento muestran como el grupo poblacional más victimizado son los adultos jóvenes, particularmente mujeres. Este artículo presenta los resultados más relevantes de una investigación efectuada con una muestra de 1.162 estudiantes universitarios, mujeres y hombres, en España. Mediante la misma se determina la tasa de victimización por este fenómeno entre estudiantes de ciencias sociales, el perfil tanto de la víctima como del stalker y se caracteriza la dinámica de la victimización.

Palabras clave: stalking, victimización, prevalencia, stalker.

\section{ABSTRACT}

Stalking constitutes a phenomenon that was criminalised in Spain in 2015. Previous research carried out on victimization by stalking shows how the most victimized are young adults, particularly women. This paper shows the most relevant results of a research conducted with a sample of 1.162 university students, women and men, in Spain. It determines the victimization rate caused by stalking amongst social sciences students; 
victim and stalker profile as well as the dynamic of this victimization are also characterized.

Key words: stalking, victimization, prevalence, stalker.

\section{Introducción}

Las conductas de stalking ganaron relevancia penal en Estados Unidos a inicios de los 90, cuando en el Estado de California se introdujo en el Código Penal la conducta consistente en la persecución reiterada, voluntaria y maliciosa o el acoso malicioso a una persona capaz de imbuir a la víctima temor racional acerca de su seguridad o la de un miembro de su familia. Más tarde la previsión de tipos delictivos relativos a este fenómeno se extendió a todos los Estados Unidos (1993), Canadá (1993), Australia (entre 1993 y 1995), Reino Unido (1997) y Nueva Zelanda (1997).

La recepción del delito de stalking en Europa se produjo fundamentalmente mediante la aprobación de la Protection from Harassment Act de 1997 en el Reino Unido. La sentida necesidad de incriminar este delito alcanzó posteriormente a otros países del ámbito continental europeo como Austria (Van der Aa, 2010), Alemania (Steinberg, 2006; Utsch, 2007), Italia (De Fazio, 2011) o Suecia. Tras la aprobación en 2011 del Convenio de Estambul, cuyo art. 34 prevé la posible incriminación del stalking en el caso de aquellas conductas intencionadas reiteradamente amenazantes que causen en la víctima temor por su seguridad, varios países han adaptado sus legislaciones a las demandas de incriminación procedentes del Consejo de Europa. Esto explica ya en 2015 la inclusión del delito de stalking en el art. 172 ter del Código Penal español.

La incriminación de esta conducta delictiva, cuanto menos en algunos países europeos, no siempre se ha visto precedida de la realización de los necesarios estudios empíricos conducentes tanto a conocer la real incidencia de este fenómeno cuanto su dinámica y efectos, lo que permitiría dotar de racionalidad el diseño de la norma incriminadora. En Estados Unidos ha sido habitual contar con información empírica relativa a determinar la tasa de victimización producida por tales conductas ya desde la National Violence Against Women Survey de 1995 (Tjaden \& Thoennes, 1998), seguida por estudios con muestras amplias realizadas a partir de ese momento (Baum, Catalano, Rand, \& Rose, 2009; Black et al., 2011; Catalano, 2012). Algo semejante ha sucedido en 
otros países anglosajones, como Australia desde la elaboración de la Womens Safety Survey de 1996 (McLennan, 1996) o Inglaterra y Gales desde la Bristish Crime Survey de 1998 (Budd \& Mattinson, 2000; Office for National Statistics, 2015) o Escocia desde la Scottish Crime and Justice Survey de 2009 (Scottish Government Social Research, 2014). En la Europa continental, pese a la existencia de estudios a nivel nacional en Alemania (Hoffmann, 2006), Italia (Istituto Nazionale di Statistica, 2007), Austria (Freidl Neuberger, Schönberger, \& Raml, 2011), Países Bajos (Van der Aa, 2010), Suecia (Dovelius, Öberg, \& Holmberg, 2006), Noruega (Narud, Friestad, \& Dahl, 2014) y Portugal (Matos, Grangeia, Ferreira, \& Azevedo, 2011), ha sido mediante la publicación de la encuesta relativa a la violencia contra las mujeres elaborada por la European Union Agency for Fundamental Rights (FRA, 2014) cuando se han conocido datos relativos a la prevalencia y características de este fenómeno en los 28 países de la Unión. Hasta este momento no se tenían datos empíricos sobre la victimización por acoso predatorio en España, en que ninguna de las cinco ediciones de la Macroencuesta de violencia contra la mujer ha analizado los supuestos de stalking.

Los estudios cuantitativos efectuados hasta ahora confirman que la población más victimizada por este patrón de conducta son mujeres menores de 30 años (Baum et al., 2009; FRA, 2014; Tjaden \& Thoennes, 1998). Fruto de la mayor incidencia de este tipo de conductas en población joven se han venido efectuando estudios que miden tanto la tasa de victimización como la dinámica de estos procesos en muestras de población universitaria. Nuevamente, dichos estudios comenzaron a realizarse en Estados Unidos (Fisher, Cullen, \& Turner, 2000; Fremouw, Westrup, \& Pennypacker, 1997; McNamara \& Marsil, 2012). En Europa, el análisis más remarcable fue realizado en el marco del proyecto "Gender-based Violence, Stalking and Fear of Crime” (2009-2011), que analizó la situación en una muestra de 21.516 mujeres universitarias residentes en Reino Unido, Alemania, Italia, España y Polonia (Feltes, Balloni, Czapska, Bodelón, \& Stenning, 2012; sobre los resultados en España vid. Igareda \& Bodelón, 2014).

Sin embargo, en relación con el grupo poblacional más victimizado por este tipo de conductas, los jóvenes adultos, los estudios previos realizados se han limitado mayoritariamente a operar con muestras exclusivamente conformadas por mujeres y a determinar la tasa de victimización con base en la percepción sobre la victimización de las propias víctimas. Sin desconocer que el stalking pueda constituir una manifestación 
de la violencia de género (Burgess et al., 1997; Douglas \& Dutton, 2001; Villacampa, 2009), con el objeto de conocer la real incidencia de la victimización por stalking en población universitaria se ha llevado a cabo el estudio cuyos resultados se exponen aquí con una muestra compuesta por mujeres y hombres. Junto a ello, además de computar como víctimas de stalking a quienes se auto-identifican como tales, se incluye también a las víctimas identificadas por las investigadoras (víctimas hetero-identificadas).

Así pues, el primer objetivo de esta investigación consiste en determinar la tasa de victimización por stalking entre la población universitaria de ambos sexos en algunas titulaciones integradas en las ciencias sociales. Constituyen ulteriores objetivos del estudio determinar las características de la víctima, establecer el perfil del victimario y conocer la dinámica de este tipo de conductas.

\section{Método}

La muestra para esta investigación estuvo compuesta por 1.162 estudiantes universitarios que cursaban derecho, criminología o investigación privada. Con la finalidad de obtener una muestra representativa de estas tres titulaciones, los participantes fueron seleccionados entre un total de 8 universidades repartidas entre las comunidades autónomas de Catalunya ( $n=626)$ y Comunidad Valenciana $(n=536)$, estratificándose la muestra en función del número total de alumnos matriculados en cada provincia. La población universitaria por provincias se distribuyó del siguiente modo: Barcelona 176.859 alumnos, Valencia 84.335, Castellón 11.996, Girona 13.799, Castellón 11.996, Tarragona 11.827 y Lleida $8.228^{1}$. El nivel de confianza de la muestra quedó fijado en el $95 \%$ y el margen de error en el $\pm 5 \%$.

El instrumento empleado en el estudio está dividido en dos partes, que componen un total de 32 preguntas. La primera estaba pensada para que fuese contestada únicamente por víctimas que se auto-identificaban como tales; mientras que la segunda se ideó para ser respondida por el resto de participantes, también por quienes no consideraban que hubiesen padecido este tipo de victimización.

La primera parte de la encuesta -para las víctimas auto-identificadas-, estuvo configurada por las preguntas 1 a 16 y se centró en cuestiones relativas a la caracterización

\footnotetext{
${ }^{1}$ Curso académico 2014/15. Fuentes: Idescat y Portal Estadístico de la Comunidad Valenciana.
} 
de la experiencia vivida (tipo de conductas padecidas, características del stalker, duración y frecuencia). La segunda parte de la encuesta -que respondieron tanto víctimas heteroidentificadas como no víctimas- englobaba el resto de preguntas (17 a 32) y su finalidad primordial fue captar las percepciones de los alumnos respecto a dos situaciones de stalking hipotéticas. Los resultados expuestos en este trabajo constituyen principalmente los deducidos del tratamiento de algunas cuestiones contenidas en la primera parte de la encuesta, relativa a la victimización.

Para elaborar esta primera parte del cuestionario se partió del contenido de la sección H de la encuesta Violence against women: an EU-wide survey que realizó la FRA con 42.000 mujeres residentes en los 28 estados miembros de la Unión Europea (FRA, 2014). Este instrumento fue adaptado para llevar a cabo esta investigación, incluyéndose en el mismo una serie de modificaciones que se relacionan a continuación. Una de las principales alteraciones fue la introducción de la distinción entre las víctimas que habían tomado consciencia de la propia victimización (víctimas auto-identificadas) y las que, a pesar de haber padecido conductas de acoso reiteradas, negaban haber sido víctimas de stalking (víctimas hetero-identificadas). Esto pudo conseguirse a través de la introducción de una primera cuestión, no prevista en la encuesta original, en la que se preguntaba directamente a los participantes si habían sufrido este tipo de victimización. En segundo término, se modificaron las posibles conductas padecidas durante el acoso, incorporando aquellos comportamientos que, a pesar de no estar incluidos en la encuesta del FRA, sí habían adquirido relevancia penal en España-adquirir productos o mercancías o contratar servicios a nombre de la víctima sin su consentimiento y hacer que una tercera persona se ponga en contacto con ella sin contar con su anuencia-.

La tercera de las variaciones en relación con la encuesta original se refiere a la frecuencia con que se producían estas conductas. Mientras la encuesta del FRA medía únicamente el número de veces que se había producido cada conducta individualmente, el instrumento utilizado en esta investigación mesuraba la frecuencia semanal con que se habían realizado la totalidad de los comportamientos. Esta modificación obedeció a una doble finalidad. Por un lado, se estimó pertinente simplificar el cuestionario, pues mientras que la encuesta de la FRA fue llevada a cabo mediante entrevistas conducidas por encuestadores profesionales, el instrumento que aquí presentamos debía ser completado autónomamente por los participantes. Por otro lado, el método utilizado por 
el instrumento europeo sólo posibilitaba conocer el número de veces en que se había producido cada conducta aislada, mientras que la fórmula introducida aquí permitía establecer la asiduidad con la que se habían producido la totalidad de conductas de acoso por semana.

El procedimiento de recogida de datos se efectuó de forma presencial entre enero y abril de 2015 en las propias universidades de los encuestados, que completaron el cuestionario individual, voluntaria y anónimamente durante el transcurso de alguna de las clases. La información recopilada fue tratada mediante el empleo del programa informático SPSS, Versión 20. Dada la falta de consenso acerca del término "stalking", de forma previa al inicio de la encuesta se proporcionó a los alumnos una definición de éste tanto oralmente como por escrito. La conceptuación facilitada definía el fenómeno como un patrón de conducta insidioso e indeseado para la víctima, capaz de generar algún efecto sobre ella tal como temor o intranquilidad (Villacampa, 2009).

En relación con las características de la muestra (tabla 1), ésta estuvo formada por 417 hombres (35.9\%) y 741 mujeres (63.8\%), con una edad comprendida entre los 18 y los 54 años $\left(\bar{X}=20.89 ; \mathrm{M}_{\mathrm{e}}=20 ; \mathrm{M}_{\mathrm{o}}=19 ; S D=4.026\right)$. De ellos, el $92.9 \%$ tenían nacionalidad española. Mientras el 53.9\% estudiaban en Catalunya, el restante $46.1 \%$ cursaban sus estudios en la Comunidad Valenciana, con la distribución por provincias, universidades y titulación cursada que aparece en la Tabla 1.

\section{Tabla 1.}

Características de la muestra $(n=1162)$

\begin{tabular}{|c|c|c|c|}
\hline & & $\mathbf{n}$ & $\begin{array}{c}\text { Porcentaje } \\
(\%)\end{array}$ \\
\hline \multirow{2}{*}{$\operatorname{Sexo}(*)$} & Hombre & 417 & 35.9 \\
\hline & Mujer & 741 & 63.8 \\
\hline \multirow{7}{*}{ Edad (*) } & 18 & 139 & 12 \\
\hline & 19 & 354 & 30.5 \\
\hline & 20 & 255 & 21.9 \\
\hline & 21 & 149 & 12.8 \\
\hline & 22 & 87 & 7.5 \\
\hline & $23-29$ & 127 & 10.9 \\
\hline & $30+$ & 40 & 3.4 \\
\hline \multirow{8}{*}{$\begin{array}{l}\text { Nacionalidad (por } \\
\text { regiones) }(*)\end{array}$} & España & 1080 & 92.9 \\
\hline & Este de Europa & 27 & 2.3 \\
\hline & Sudamérica & 23 & 2 \\
\hline & Sur de Europa & 7 & 0.6 \\
\hline & Oeste de Europa & 7 & 0.6 \\
\hline & Centro de Europa & 5 & 0.4 \\
\hline & Centroamérica & 4 & 0.3 \\
\hline & Norteamérica & 2 & 0.2 \\
\hline
\end{tabular}




\begin{tabular}{llcc} 
& Norte de África & 1 & 0.1 \\
\hline Comunidad Autónoma & Catalunya & 626 & 53.9 \\
& Comunidad Valenciana & 536 & 46.1 \\
\hline Provincia & Barcelona & 489 & 42.1 \\
& Valencia & 335 & 28.8 \\
& Alicante & 119 & 10.2 \\
& Castellón de la Plana & 82 & 7.1 \\
& Tarragona & 51 & 4.4 \\
& Lleida & 48 & 4.1 \\
& Girona & 38 & 3.3 \\
\hline Universidad (*) & Universidad 1 & 81 & 7 \\
& Universidad 2 & 38 & 3.3 \\
& Universidad 3 & 48 & 4.3 \\
& Universidad 4 & 408 & 35.1 \\
& Universidad 5 & 51 & 4.4 \\
& Universidad 6 & 335 & 28.8 \\
& Universidad 7 & 119 & 10.2 \\
& Universidad 8 & 82 & 7.1 \\
\hline Estudios (*) & Derecho & 716 & 61.6 \\
& Criminología & 370 & 31.8 \\
& Investigación Privada & 76 & 6.5 \\
\hline
\end{tabular}

(*) Algunas categorías no suman el 100\% como consecuencia de los redondeos o de la falta de respuesta de algunos participantes.

\section{Medidas}

Con la finalidad de conocer la prevalencia de estas conductas, así como el perfil de la víctima y el del acosador, se incorporaron en la encuesta las siguientes cuestiones:

- Para determinar el perfil de la víctima, se pidió a los encuestados que indicaran su sexo, nacionalidad, provincia donde residían, universidad en la que cursaban sus estudios y titulación en curso.

- Para averiguar qué tipo de comportamientos habían integrado el patrón conductual,, se preguntó a las mismas cuáles de las siguientes conductas habían sufrido : (1) enviar a la víctima mensajes de correo electrónico, mensajes de texto (SMS) o mensajes instantáneos con contenido ofensivo o amenazador; (2) enviarle cartas o tarjetas ofensivas o amenazadoras; (3) hacerle llamadas telefónicas ofensivas, amenazadoras o silenciosas; (4) publicar comentarios ofensivos sobre la víctima en Internet; (5) compartir fotografías o videos íntimos de la víctima a través de Internet o del teléfono móvil; (6) merodear o esperarle en el exterior de su casa, lugar de trabajo o centro de estudios sin una razón legítima; (7) seguirla deliberadamente; (8) adquirir productos o mercancías o 
contratar servicios a su nombre y sin su consentimiento y (9) dañar su propiedad o sus bienes materiales deliberadamente.

- Para establecer el perfil del acosador, se comenzó preguntando a las víctimas por el sexo del stalker, ofreciendo las siguientes opciones de respuesta: (1) Hombre; (2) Mujer; (3) Eran tanto hombres como mujeres.

- Se preguntó además por la relación que el ofensor mantenía con la víctima de forma previa al inicio del acoso, incluyéndose como opciones que el stalker era: (1) su marido/esposa; (2) su novio/a; (3) su ex marido/esposa; (4) su ex novio/a; (5) su jefe/a; (6) un compañero de trabajo; (7) un compañero/a de estudios; (8) un cliente o paciente suyo; (9) su profesor, entrenador o coach; (10) su doctor u otro trabajador de la salud; (11) un miembro de su familia; (12) alguien a quien acaba de conocer; (13) un amigo; (14) un conocido; (15) alguien a quien usted no conoce; (16) no lo sabe.

- Quiso también conocerse el número de personas implicadas en la comisión de los hechos, ofreciéndose como opciones de respuesta: (1) una; (2) dos; (3) tres o más; (4) una o más, dependiendo del incidente.

- Al objeto de conocer la dinámica de la victimización, se comenzó preguntando por la duración del acoso, incluyéndose como opciones de respuesta: (1) unos pocos días; (2) entre unos pocos días y un mes, (3) más de un mes y menos de 3 meses, (4) más de 3 meses y menos de 6 meses, (5) más de 6 meses y menos de 1 año; (6) más de 1 y menos de 2 años; (7) más de 2 y menos de 3 años; (8) más de 3 y menos de 4 años; (9) más de 4 y menos de 5 años; (10) más de 5 y menos de 10 años; (11) más de 10 años. Se preguntó, así mismo, por la frecuencia semanal con que se producían estas conductas, ofreciéndose como opciones: (1) menos de 2 veces; (2) 2 veces; (3) 3 veces; (4) 4 veces; (5) 5 o más veces. Las categorías de duración y frecuencia del stalking fueron en algunos casos acumuladas para obtener un tratamiento de los datos más adecuado. 


\section{Resultados}

\subsection{Prevalencia vital de victimización por stalking}

Tomando como base el concepto de stalking antes mencionado, se preguntó a los participantes si habían sido acosados alguna vez en estos términos, de manera que el padecimiento de esta situación permitiera determinar la tasa de victimización en la muestra seleccionada. Un total de 152 alumnos (13.1\%) respondieron afirmativamente a esta cuestión, por lo que fueron clasificados como víctimas auto-identificadas. Paralelamente, se preguntó a las personas que respondieron negativamente a dicha pregunta si habían padecido de forma reiterada alguna de las conductas comúnmente identificadas como stalking por los investigadores. Adicionalmente, 314 participantes (27\%) afirmaron haber padecido reiteradamente alguna de dichas conductas, catalogándose como víctimas hetero-identificadas.

Cabe concluir, sumando los porcentajes de víctimas auto y hetero-identificadas, que un $40 \%$ de la muestra ( $n=466)$ había sido víctima de conductas de stalking.

En lo que a prevalencia se refiere, los resultados de esta investigación confirman los que emanan de precedentes estudios. Mientras con muestras de población en general la prevalencia de victimización se sitúa entre un $7 \%$ y un $16 \%$ en las mujeres y entre un 2\% y un 6\% en los hombres (Baum et al., 2009; Matos et al., 2011; Tjaden \& Thoennes, 1998), en investigaciones con muestras conformadas por estudiantes universitarios tales porcentajes se sitúan entre el $9.2 \%$ y el $35.2 \%$ en las mujeres y el $2 \%$ y el $30.8 \%$ en hombres (Bjerregaard, 2000; Feltes et al., 2012; National Union of Students, 2011). En concreto, en relación con la muestra española que intervino en la encuesta del FRA, la tasa de victimización para España de población en general se estableció en el 11\% (FRA, 2014), muy por debajo del $40 \%$ que arroja este estudio.

Debe subrayarse que poco más de un cuarto de las víctimas se identificaron como tales (13.1\% del 40\% de víctimas). En esto, los resultados confirman los de precedentes análisis que miden auto y hetero-identificación sobre victimización por stalking en población universitaria (McNamara \& Marsil, 2012), los cuales informan acerca de un $12 \%$ de alumnos auto-identificados como víctimas frente al $42.5 \%$ de estudiantes que resultaron haberlo sido. Por tanto, la tasa de victimización percibida en la población 
universitaria encuestada se aproxima a aquella detectada en España, que se sitúa en un 14\% (Feltes et al., 2012).

Constatada la reducida auto-conciencia sobre esta victimización, se preguntó a las víctimas hetero-identificadas el motivo por el cual no se reconocían a sí mismas como tales. Un 34.7\% de ellas afirmó que la razón era que la situación no les había producido miedo ni intranquilidad, un $30.3 \%$ que las conductas no tuvieron la duración suficiente para ser consideradas acoso y un $27.9 \%$ que la conducta no había sido lo suficientemente grave. Por tanto, la motivación ofrecida por éstas atendía a la escasa gravedad de la conducta padecida para no auto-identificarse como víctima. La apelación a la escasa incidencia de estas conductas fue más evidente en el caso de los hombres que en el de las mujeres. Mientras que las mujeres fueron más propensas que los hombres a indicar que la razón había sido la corta duración del fenómeno $\left(\chi_{(1, N=312)}^{2}=8.66 ; \rho=.003, \Phi=.109\right)$, éstos fueron más proclives a manifestar que la causa era que el padecimiento de las conductas no les había ocasionado sensación de miedo o de intranquilidad $\left(\chi_{(1, N=312)}^{2}=\right.$ $4,29 ; \rho=.038, \Phi=.117)$.

\subsection{Características de la víctima}

Seguidamente se expondrán algunas características socio-demográficas de las personas identificadas como víctimas de stalking. Atendiendo a lo escaso de los datos personales requeridos en el cuestionario empleado, siguiendo el patrón de los instrumentos empleados con población universitaria (Fremouw et al., 1997; Haugaard \& Seri, 2003), quizá los resultados más reveladores para explicar la victimización son los ofrecidos por la variable sexo.

En referencia a esta cuestión, cabe destacar que las víctimas auto-identificadas fueron en su mayoría mujeres (80.3\% mujeres; $19.7 \%$ hombres). Mientras el 16.5\% del total de mujeres encuestadas se reconocieron como víctimas de stalking, únicamente el 7.2\% de los hombres se identificaron como tales, existiendo una diferencia estadísticamente significativa entre uno y otro sexo respecto a la auto-identificación $\left(\chi^{2}\right.$ $(1, N=1158)=20.1 ; \rho<.001, \Phi=.132)$. Según los resultados de la regresión logística realizada, las mujeres tienen una propensión 2.52 veces mayor que los hombres a autoidentificarse como víctimas de stalking. 
Por el contrario, atendiendo al sexo de las víctimas hetero-identificadas, el estudio desveló que éstas eran casi a partes iguales hombres (25.4\%) y mujeres (27.8\%), no existiendo una diferencia estadísticamente significativa en relación con la victimización hetero-identificada $\left(\chi_{(1, N=1158)}^{2}=0.7 ; \rho=.408\right)$.

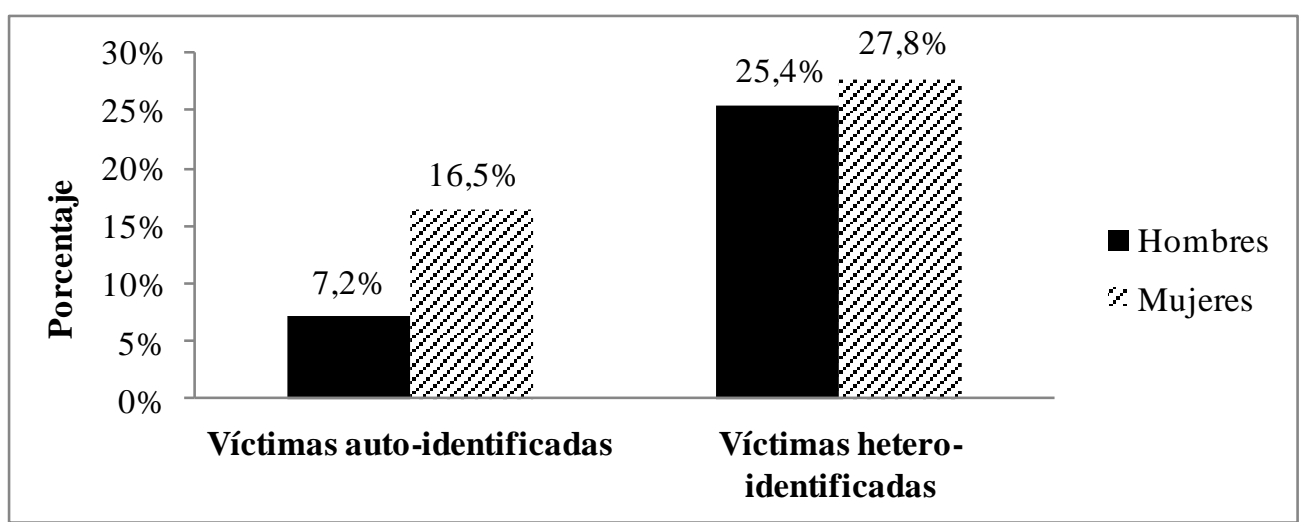

Figura 1: Comparativa entre la victimización auto-identificada y hetero-identificada, por sexo.

Si bien en términos globales un $71 \%$ de las víctimas fueron mujeres y un $29 \%$ hombres, tal oscilación se debe a la composición mayoritariamente femenina de la muestra. Sin embargo, determinando la tasa de victimización por stalking en función del sexo, puede observarse que un $44 \%$ de las mujeres encuestadas y un $33 \%$ de los hombres fueron víctimas de estas conductas.

Atendiendo a que las ratios de auto y hetero-identificación sobre victimización por stalking revelaron tal disparidad respecto del sexo de las víctimas, no confirmada por la determinación de la tasa de victimización por sexos, se procedió a la realización de una regresión logística para valorar el mayor o menor riesgo de ser victimizado por estas conductas en función del sexo de la víctima. Los resultados de dicha regresión logística revelaron que el riesgo de padecer victimización por stalking es 1.6 veces mayor en caso de ser mujer, lo que supone un incremento no sustancial de la probabilidad de padecer estas conductas.

En relación con el sexo de las víctimas, los resultados ofrecidos por este estudio contradicen los que surgen de la mayor parte de investigaciones efectuadas hasta el momento en población general, probablemente porque de forma mayoritaria miden la percepción de la victimización. Con carácter general éstos confirman la mayor 
victimización de las mujeres respecto de los hombres por este tipo de conductas (Catalano, 2012; Scottish Government Social Research, 2014; Tjanden \& Thoennes, 1998). Los resultados antes mencionados también resultan parcialmente discordantes con los arrojados por estudios efectuados en población universitaria, que igualmente informan acerca de la mayor victimización de mujeres, si bien de manera menos significativa (Bjerregaard, 2000; Logan, Leukefeld, \& Walker, 2000).

En relación con la edad de las víctimas, la distribución aparece reflejada en la Figura 2. La mediana de edad de las víctimas fue de 20 años, al igual que la de la muestra en su conjunto. La edad no constituyó un factor determinante para explicar la victimización $\left(\chi^{2}(1, N=1162)=42.38 ; \rho=.066\right)$.

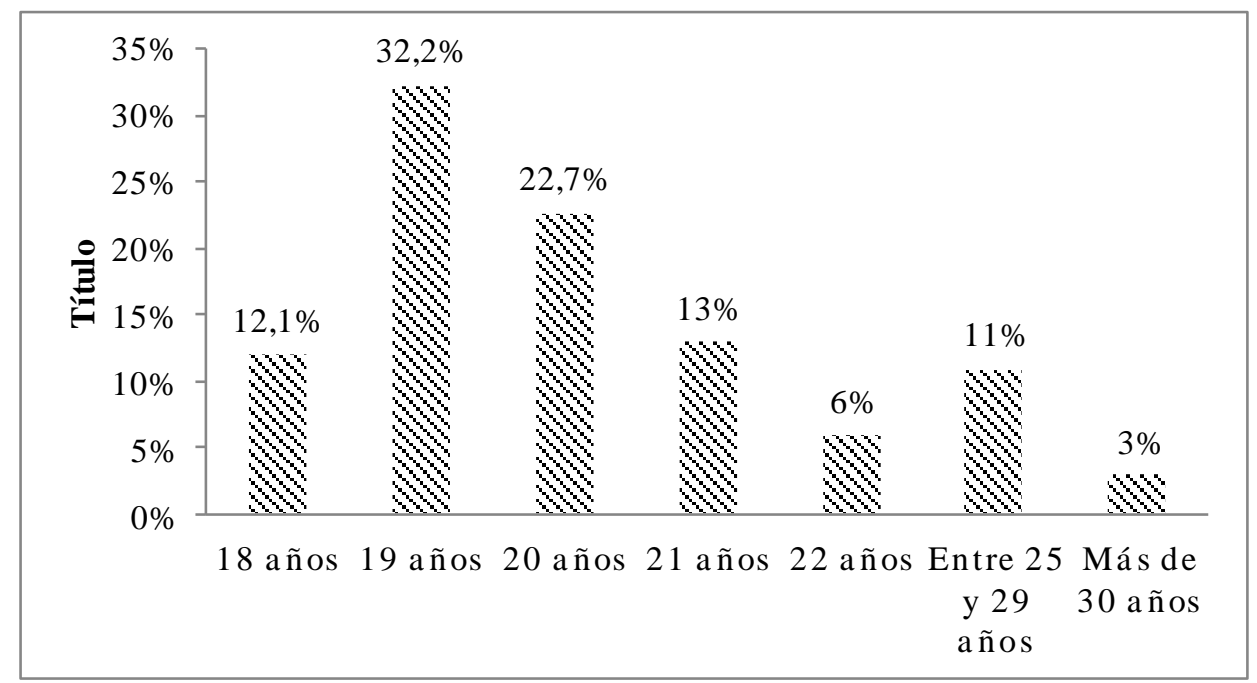

Figura 2: Edad de las víctimas.

La región donde residían los participantes sí influyó en la tasa de victimización. Tanto la comunidad autónoma $\left(\chi^{2}(1, N=1162)=12.09 ; \rho=.001, \Phi=.123\right)$ como la provincia $\left(\chi^{2}{ }_{(6, N=1162)}=15.24 ; \rho=.019, \Phi=.130\right)$ arrojaron diferencias estadísticamente significativas respecto a la victimización. El porcentaje de víctimas fue significativamente más elevado en Catalunya (60\%) que en la Comunidad Valenciana (40\%). También la auto-identificación como víctima se produjo más en Catalunya (16.9\%) que en la Comunidad Valenciana (8.6\%). Por provincias, la mayor tasa de victimización es directamente proporcional al tamaño de la capital de cada una de ellas, de manera que en provincias con una capital más poblada la tasa de victimización fue 
mayor que en las de entornos más rurales (Barcelona 46.8\%; Valencia 25.1\%; Alicante 9.9\%; Tarragona 5.4\%; Castellón de la Plana 4.9\%; Lleida 4.7\% y Girona 3.2\%). Se observa, no obstante, que la mayor tasa de auto-identificación se produjo en capitales de provincia más pequeñas en comparación con los núcleos poblacionales de mayor tamaño. En Catalunya la provincia con mayor tasa de víctimas auto-identificadas fue Tarragona (21.6\%), mientras en la Comunidad Valenciana fue Castellón de la Plana (9.8\%), seguida de Alicante $(9.2 \%)$ y Valencia (8.1\%). Confirmándose la mayor victimización por este tipo de conductas en Catalunya respecto de la Comunidad Valenciana, los datos apuntan a una mayor tasa real de victimización en grandes núcleos urbanos frente a la más clara conciencia sobre el fenómeno, reflejada en la auto-identificación, en ciudades de menor tamaño o en entornos más rurales. Sobre este particular, el estudio ni confirma ni desmiente resultados alcanzados por anteriores investigaciones, dado que no se ha analizado la significación del entorno urbano o rural en la victimización por stalking.

La nacionalidad de los participantes, sin embargo, no resultó estadísticamente significativa para explicar esta victimización $\left(\chi_{(1, N=1162)}^{2}=42.38 ; \rho=.066\right)$.

Por último, la titulación que los participantes estaban cursando estuvo asociada con la victimización por estas conductas $\left(\chi^{2}(2, N=1162)=10.76 ; \rho=.005, \Phi=.121\right)$. Se observó que la mayor parte de víctimas cursaban derecho (56\%), seguidas por las que realizaban criminología (35\%) e investigación privada (9\%). En este aspecto, los resultados de este estudio ni confirman ni desmienten conclusiones alcanzadas en investigaciones precedentes, dado que no se había analizado anteriormente la incidencia de esta variable. Lo que sí resulta revelador es que siendo los estudiantes de investigación privada los menos victimizados fueron justamente los que más se auto-identificaron como víctimas (25\%), seguidos por los estudiantes de criminología (15.9\%) y derecho (10.3\%). Puede aventurarse que esta mayor auto-identificación podría deberse al mejor conocimiento de este proceso que pueden tener estudiantes de titulaciones donde el mismo se aborda, como investigación privada o criminología, frente a aquellas, como derecho, en que el análisis de éste no se ha producido hasta la vigencia del delito de stalking, con carácter posterior a la realización de la encuesta. 


\subsection{Características del stalker}

Respecto de las características del ofensor, los datos que se ofrecen se extraen exclusivamente de las respuestas al cuestionario que ofrecieron las víctimas autoidentificadas, puesto que no resultaba coherente preguntar por el stalker a quien no se consideraba víctima.

\section{Sexo del stalker}

Los participantes indicaron que en la mayor parte de casos las conductas de acoso fueron realizadas por varones (Figura 3). Los resultados del estudio confirman en esto los procedentes tanto de anteriores análisis sobre población en general (Black et al., 2011; FRA 2014; Matos et al., 2011; Tjaden \& Thoennes, 1998), como con muestras de estudiantes universitarios (Bjerregaard, 2000; Feltes et al., 2010; National Union of Students, 2011), que mayoritariamente identifican a los stalkers con hombres.

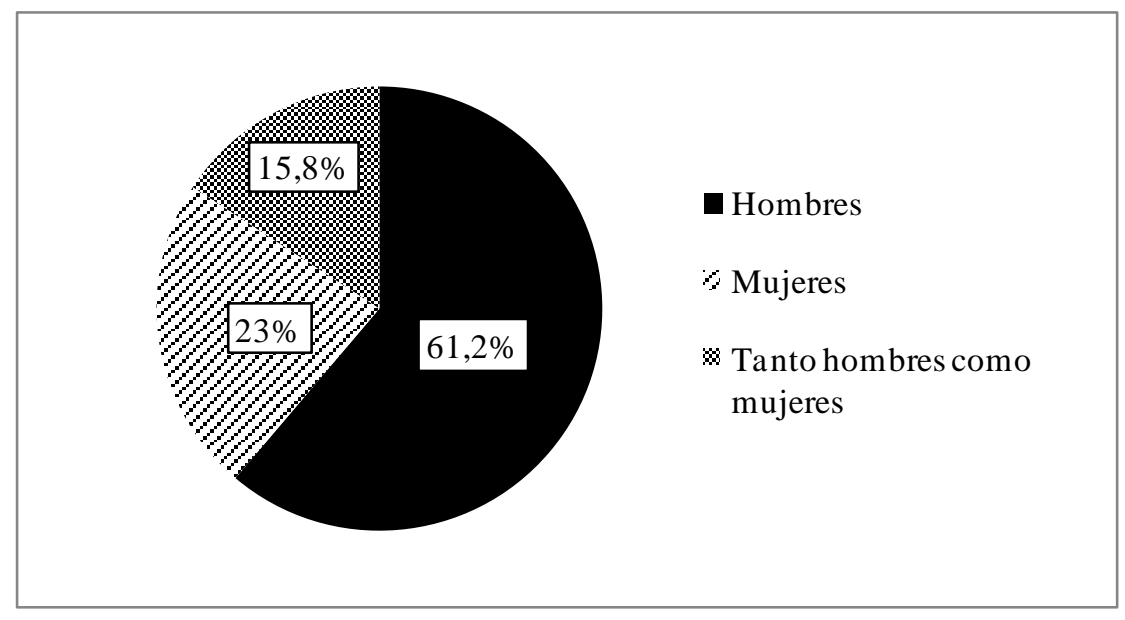

Figura 3: Sexo del stalker.

En diversos estudios con población en general y universitaria se pone de manifiesto que el sexo del stalker está relacionado con el de la víctima, de manera que mientras las mujeres acostumbran a ser mayoritariamente acosadas por hombres, los varones son victimizados tanto por hombres como por mujeres (Bjerregaard, 2000, p. 395; Matos et al., 2011). Tal extremo no ha podido constatarse absolutamente en este estudio, en que no se halló una relación significativa entre el sexo de la víctima y el del ofensor ( $\chi^{2} \quad(2, \mathrm{~N}=152)$ $=5.02 ; \rho=.081)$. Pese a la ausencia de significación estadística, en los supuestos en que 
la víctima fue mujer mayoritariamente los acosadores fueron hombres (ofensor hombre $=$ $66 \%$, ofensora mujer $=21 \%$, tanto hombres como mujeres $=13 \%$ ), mientras que en los casos con víctima varón, el sexo de los ofensores estuvo más equilibrado (hombres $=$ $43.4 \%$, mujeres $=33.3 \%$, hombres $/$ mujeres $=23.3 \%$ ) .

Nuevamente el análisis estadístico de los datos reveló la existencia de diferencias significativas en torno a las variables sexo del acosador y número de personas implicadas en el proceso de stalking $\left(\chi_{(6, N=152)}^{2}=57.05 ; \rho<.001, \Phi=.433\right)$. Mientras el $80.6 \%$ de los hombres había actuado en solitario, las mujeres habían preferido actuar en grupo. Concretamente, intervinieron conjuntamente con otras mujeres en el $45.7 \%$ de los casos ( $20 \%$ con otra mujer y $25.7 \%$ con 3 o más mujeres), actuando solas únicamente en el $42.9 \%$.

Por último, respecto al sexo de los intervinientes en casos de acoso grupal -aquél en que estuvieron implicadas 3 o más personas-, cabe destacar que éste fue mayormente perpetrado por grupos mixtos (44\%), seguidos de grupos formados únicamente por mujeres $(36 \%)$ y únicamente por hombres $(20 \%)$.

\section{Relación previa}

Respecto a la relación previa existente entre víctima y ofensor, los datos revelan que la mayor parte de víctimas conocían a su acosador con anterioridad al inicio del stalking $(81.2 \%)$ (Figura 4$)$.

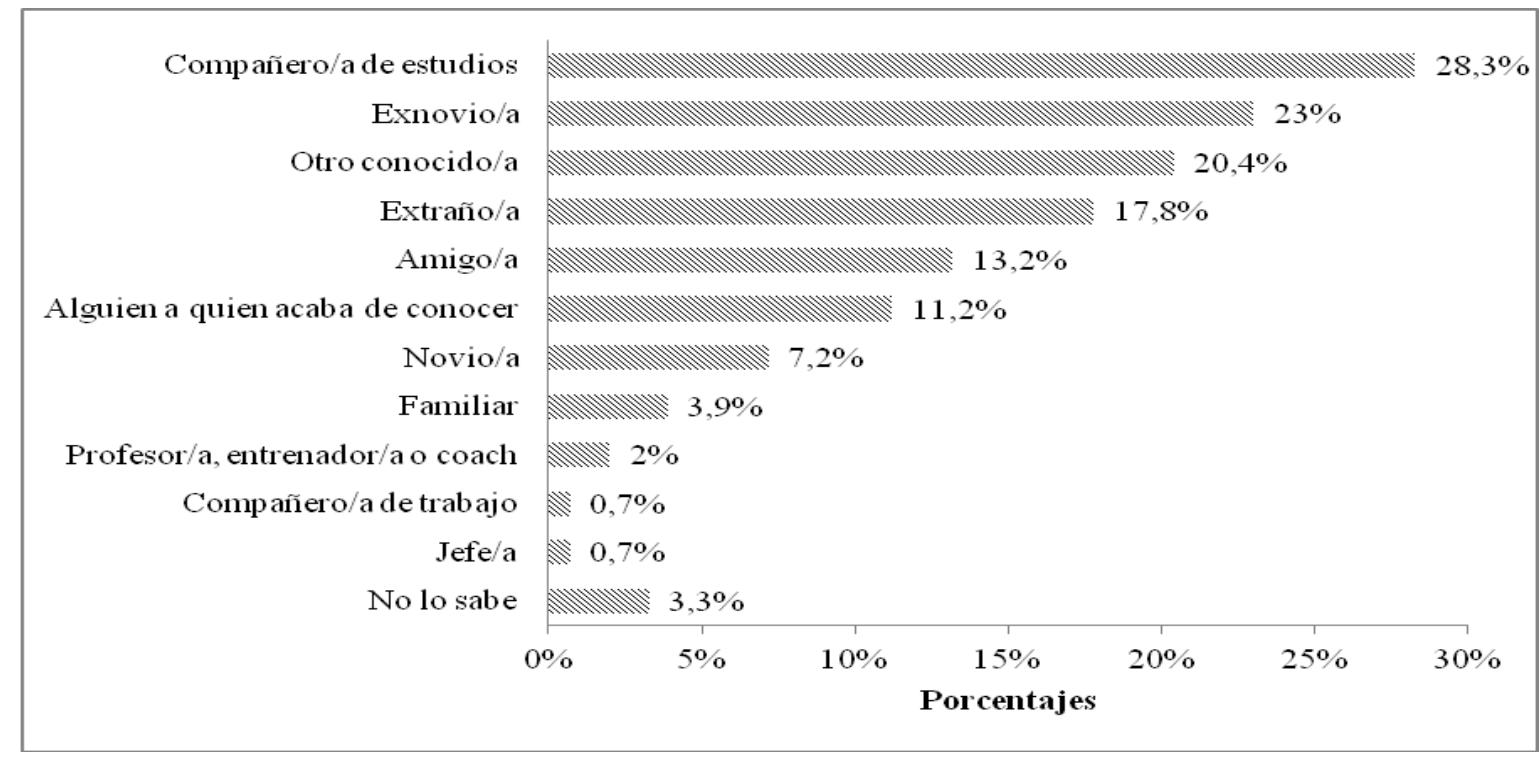

Figura 4: Relación previa entre víctima y agresor. 
La mayor parte de supuestos de stalking en este estudio proceden de personas del entorno de la víctima. Agrupando los porcentajes deducidos de la pregunta de respuesta múltiple acerca de la relación previa entre víctima y agresor, el 25\% procedió de personas que mantenían o habían mantenido una relación sentimental con la víctima, el 37\% de los casos de quienes mantuvieron algún tipo de relación profesional, de amistad o familiar con ésta, el $24 \%$ de personas relacionadas con ella de forma más esporádica y sólo el 13\% de los casos de extraños. La investigación efectuada corrobora los resultados procedentes de anteriores estudios, en el sentido de destacar que el stalking procede mayoritariamente de personas cercanas a la víctima (Björklund, Häkkänen-Nyholm, Sheridan, \& Roberts, 2010; Fisher et al., 2000; FRA, 2014; Matos et al., 2011; Tjadenn \& Thoennes, 1998), aun cuando en las respuestas no se incluyera al cónyuge o ex cónyuge, posiblemente debido a la edad de la población estudiada.

Se ha confirmado una fuerte asociación entre las variables sexo del stalker y relación víctima-ofensor, de manera que en acosos producidos por personas muy próximas a la víctima o por extraños la mayoría de stalkers son hombres, mientras en relaciones menos próximas la proporción de stalkers por sexos no está tan desequilibrada. Así, los stalkers que eran o habían sido compañeros de estudios de la víctima eran prácticamente a partes iguales hombres (37.2\%), mujeres $(34.9 \%)$ y personas de ambos $\operatorname{sexos}(27.9 \%)\left(\chi_{(2, N=152)}^{2}=14.87 ; \rho<.001 ; \Phi=.313\right)$. Por el contrario, aunque sin significación estadística, cuando el stalker había sido el novio o el exnovio de la víctima éste era un varón en un $70 \%$ y $83 \%$ de los casos respectivamente. Lo mismo que cuando era un miembro de su familia, en que también en un $80 \%$ de los casos el ofensor era un hombre. En el otro extremo del espectro relacional, cuando los hechos habían sido perpetrados por desconocidos, éstos tenían significativamente más probabilidad de ser cometidos por personas de sexo masculino $\left(\chi_{(2, N=152)}^{2}=6.03 ; \rho=.049 ; \Phi=.199\right)$. En estos casos, los stalkers hombres suponían el $59.3 \%$ de los casos, mientras que las mujeres representaban únicamente el $11.1 \%$. Algo semejante sucedía en los casos de stalking cometido por alguien que la víctima acababa de conocer, en que en un 93\% de los supuestos el sujeto activo era un hombre. 


\section{Número de ofensores}

Generalmente estas conductas habían sido llevadas a cabo por 1 sola persona (61.2\%), aunque ocasionalmente existían también situaciones en las que el acoso había sido perpetrado por 2, 3 o más sujetos (Figura 5). Sobre este particular los resultados de la investigación confirman los que se deducen de otras efectuadas con carácter previo (Baum et al., 2009; Budd \& Mattinson, 2000). En otros supuestos, sin embargo, los stalkers habían sido 1 o más dependiendo del incidente (13.8\%), es decir, respecto de la misma víctima, algunos incidentes habían sido protagonizados por 1 solo acosador, mientras que otros fueron perpetrados por 2 o más sujetos.

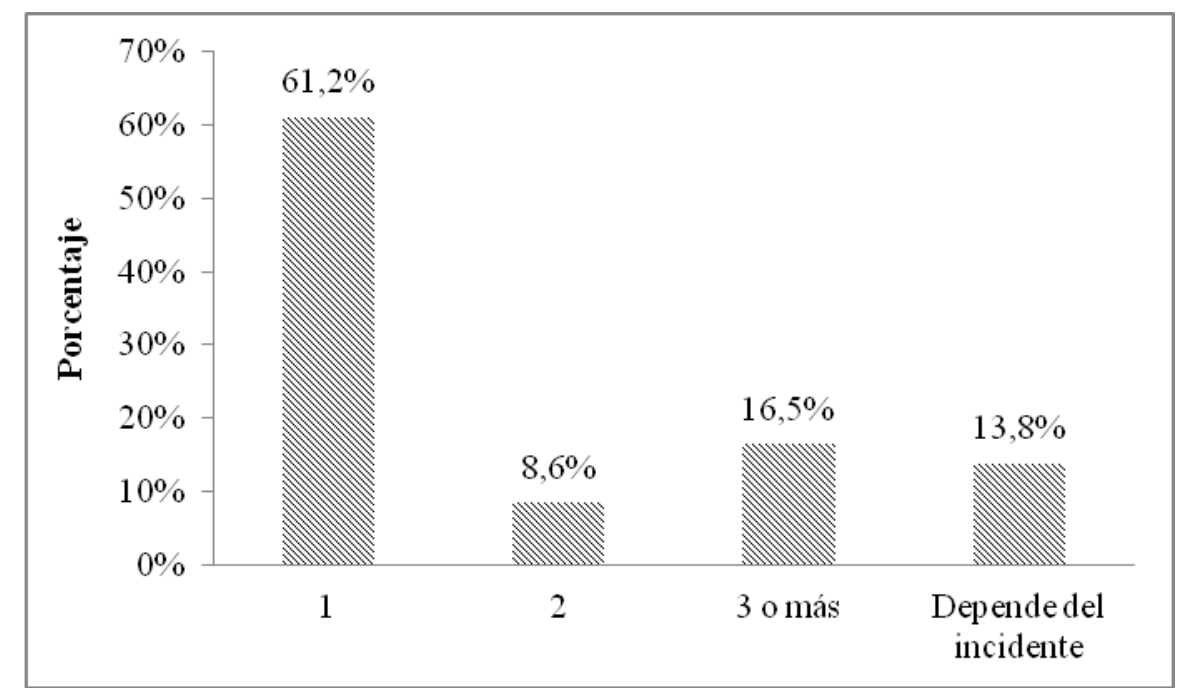

Figura 5: Número de stalkers.

El patrón del stalker solitario se confirma al cruzar las variables del número de ofensores con la relación que éste o éstos mantienen con la víctima, fortaleciéndose como más próximo se halla a la víctima. En este sentido, se ha constatado que generalmente los acosos que procedían de personas que ésta conocía bien acostumbraron a realizarse en solitario $(69.7 \%$ de los casos $)\left(\chi^{2}{ }_{(3, N=152)}=9.61 ; \rho=.022, \Phi=.251\right)$. El porcentaje de acosadores solitarios decrece al 50\% de los supuestos allí donde la víctima no sabía quién era su acosador $\left(\chi^{2}{ }_{(3, N=152)}=9.51 ; \rho=.023, \Phi=.243\right)$. 


\subsection{Dinámica de la victimización}

Los resultados expuestos en este apartado se han elaborado exclusivamente a partir de las respuestas a los cuestionarios ofrecidas por los participantes auto-identificados como víctimas, con excepción de los referidos al tipo de conducta padecida, en que también se ha contado con las respuestas de las víctimas hetero-identificadas.

\section{Tipo de conductas}

Atendiendo a que la media de conductas padecidas por las víctimas fue de 2,1, las más frecuentemente realizadas por los stalkers entre las víctimas que se auto-identificaron como tales fueron a) enviar correos electrónicos, mensajes de texto y mensajes instantáneos ofensivos o amenazadores, b) merodear o esperar a la víctima fuera de su casa, lugar de trabajo o centro educativo, c) efectuarle llamadas telefónicas ofensivas, amenazadoras o silenciosas y d) seguirla deliberadamente (Figura 6). En el caso de las víctimas hetero-identificadas, las conductas más habitualmente realizadas por el stalker, que afectan a más del $30 \%$ de las víctimas, fueron el envío de correos electrónicos o mensajes de texto o instantáneos, la realización de llamadas telefónicas y hacer que una tercera persona se pusiera en contacto con la víctima (Figura 6).

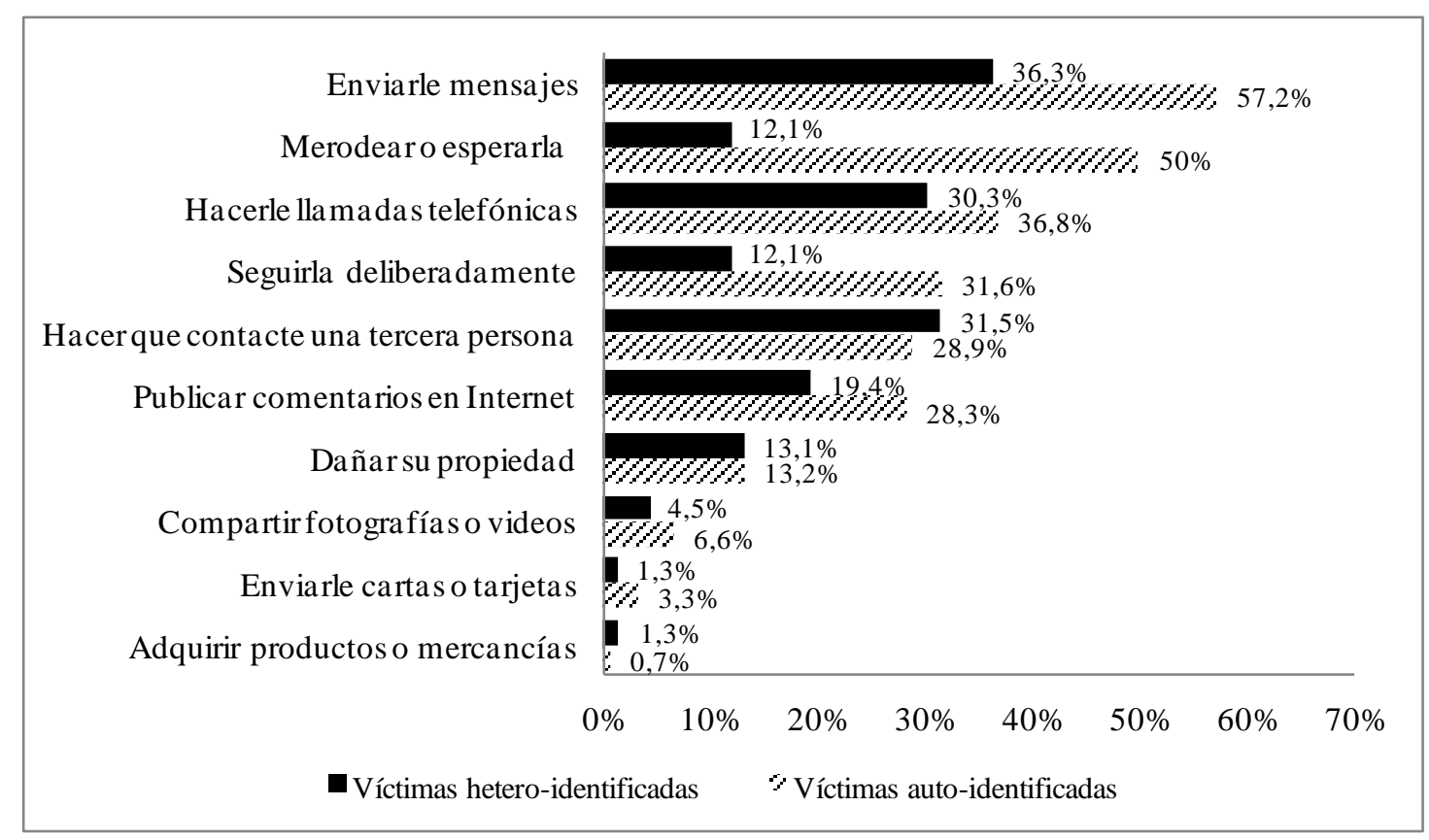

Figura 6: Tipo de conductas padecidas. 
Dado que la conducta consistente en el envío de correos electrónicos, mensajes de texto o mensajes instantáneos ofensivos o amenazadores fue la más común en ambos casos, puede indicarse que el cyberstalking constituye la forma de stalking más generalizada en este grupo de edad. Tal aspecto lo confirma la suma para ambos grupos de víctimas de los porcentajes - calculados sobre 100- correspondientes tanto a la conducta mencionada como a las de publicar comentarios ofensivos sobre la víctima en internet, así como compartir fotografías o vídeos íntimos de la misma a través de internet o del teléfono móvil. El porcentaje acumulado de tales conductas representó el $40 \%$ de las padecidas en el caso de las víctimas auto-identificadas y el $37 \%$ en el caso de las hetero-identificadas, repartiéndose el $60 \%$ y el $63 \%$ respectivamente restantes entre las otras 7 conductas incluidas en el cuestionario. Debe aclararse, además, que en ese porcentaje restante en ambos casos se incluye la conducta consistente en hacer llamadas telefónicas ofensivas, amenazadoras o silenciosas a la víctima (19\% víctimas autoidentificadas y $14 \%$ víctimas hetero-identificadas), que de ser efectuadas a través de telefonía móvil podrían también considerarse supuestos de cyberstalking.

Sin embargo, más allá de compartir como más comunes los comportamientos relacionados con el cyberstalking, el tipo de conductas padecidas por uno y otro tipo de víctimas (las auto y las hetero-identificadas) difiere. Pudo observarse que en el caso de las víctimas auto-identificadas comportamientos que persiguen la aproximación física a éstas son muy claramente prevalentes, a diferencia de lo que sucede con las víctimas hetero-identificadas. De hecho, en el análisis bivariante relativo al tipo de conducta padecido en función de que la víctima se identificase o no como tal, se observó que la significación estadística era más evidente en las conductas consistentes en merodear o esperar a la víctima a la salida de su casa, lugar de trabajo o centro educativo $\left(\chi^{2}(1, N=1162)\right.$ $=79.61 ; \rho<001, \Phi=.291)$ o seguirla deliberadamente $\left(\chi^{2}(1, N=1162)=25.82 ; \rho<001\right.$, $\Phi=.313)$. Éstas, además, son mayoritariamente padecidas por mujeres, que representaron alrededor del 80\% de las víctimas en ambos casos.

En la elevada prevalencia de conductas encaminadas a iniciar una comunicación con la víctima, los resultados de este estudio son consistentes con la literatura existente, que además sitúa en segundo lugar las conductas tendentes a buscar proximidad física con la misma (Black et al., 2011; FRA, 2014; McNamara \& Marsil, 2012). No obstante, en lo que no se ven confirmados, seguramente debido a la práctica ausencia de 
comparativas entre víctimas auto y hetero-identificadas, es en la oscilación de la prevalencia del tipo de conducta en función de que las víctimas se identifiquen o no como tales. La remarcable diferencia existente entre víctimas auto y hetero-identificadas en lo que a conductas que buscan la aproximación física se refiere parece sugerir que es precisamente el padecimiento de este tipo de conductas lo que conduce a las víctimas a identificarse como tales.

Esta deducción resulta coherente con los porcentajes que arroja la respuesta a la pregunta incluida únicamente en el cuestionario efectuado a las víctimas autoidentificadas relativa a que indicaran cuáles de las conductas expuestas les parecían más graves, entendiendo por tales aquellas que habían tenido un mayor impacto en su salud física o psicológica. Un $44.1 \%$ expusieron que merodear o esperar a la persona fuera de su casa, lugar de trabajo o centro de estudios era una de las conductas de mayor gravedad. Le seguían en importancia conductas como seguir deliberadamente a la víctima (32.2\%); enviarle correos electrónicos, mensajes de texto (SMS) o mensajes instantáneos ofensivos o amenazadores (28.9\%); realizarle llamadas telefónicas ofensivas, amenazadoras o silenciosas $(23 \%)$ o compartir fotografías o vídeos de la víctima a través de Internet o del teléfono móvil (21.7\%). Según las víctimas, las conductas que les supusieron una menor afectación, quizás también por ser las padecidas con una menor frecuencia, fueron recibir cartas o postales ofensivas o amenazadoras (6.6\%) y adquirir productos o mercancías o contratar servicios a su nombre y sin su consentimiento $(2 \%)$.

\section{Frecuencia}

Generalmente las conductas de stalking muestran las características de un patrón de conducta, en el sentido de que se repiten varias veces por semana, como ha podido observarse en estudios anteriores que han medido la frecuencia (Baum et al., 2009; Fisher et al., 2000; Matos et al., 2011). Las víctimas indicaron que, en la mayoría de casos, los episodios de acoso se daban entre 2 y 5 veces a la semana o 6 o más veces por semana (Figura 7). 


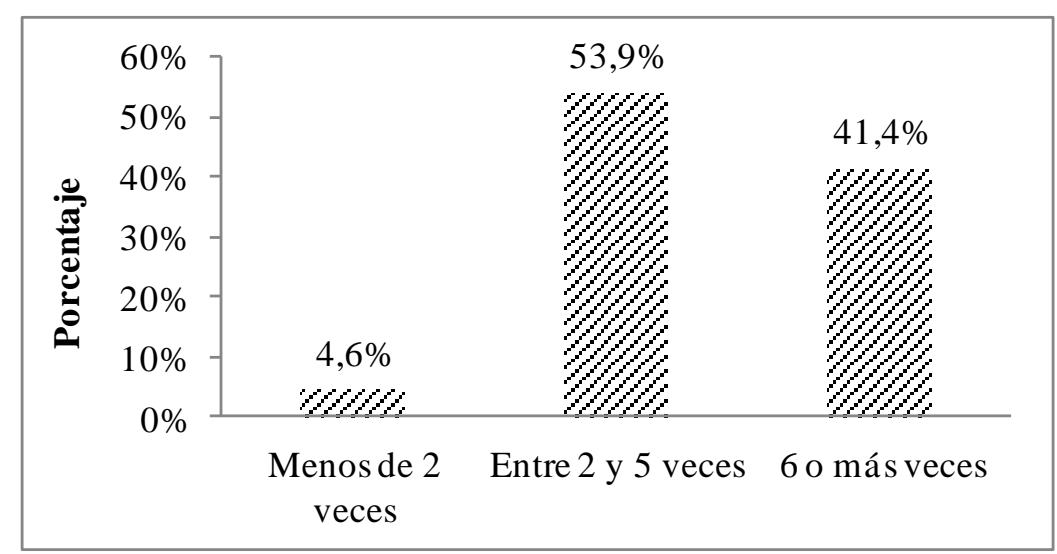

Figura 7: Frecuencia de las conductas.

\section{Duración}

Respecto a la duración, los resultados de este estudio no confirman absolutamente los de los precedentes. La literatura existente informa acerca de que la duración mayoritaria de los supuestos de acoso se sitúa en unos pocos meses, dilatándose varios años únicamente el 10\% de éstos (Catalano, 2012; FRA, 2014; Matos et al., 2012; National Union of Students, 2011).

En la presente investigación no se ha objetivado la existencia de un patrón claro en cuanto a la duración de las conductas, pues resultaron porcentajes parecidos respecto a los diferentes periodos de duración (Figura 8). No obstante, puede observarse como los supuestos de acoso que superan el año ascendieron al 28.3\%, siendo que en el $9.2 \%$ de los casos el acoso se produjo por más de 3 años. Sí puede afirmarse, sin embargo, que los acosos más breves procedían de personas que la víctima apenas conocía (70\% de los casos breves), mientras que los que se dilataron más en el tiempo, entre 1 y 3 años, habían sido realizados por personas del entorno de la víctima (50\% de un miembro de su familia, $41 \%$ del novio o ex novio, $26 \%$ de compañeros de estudios). 


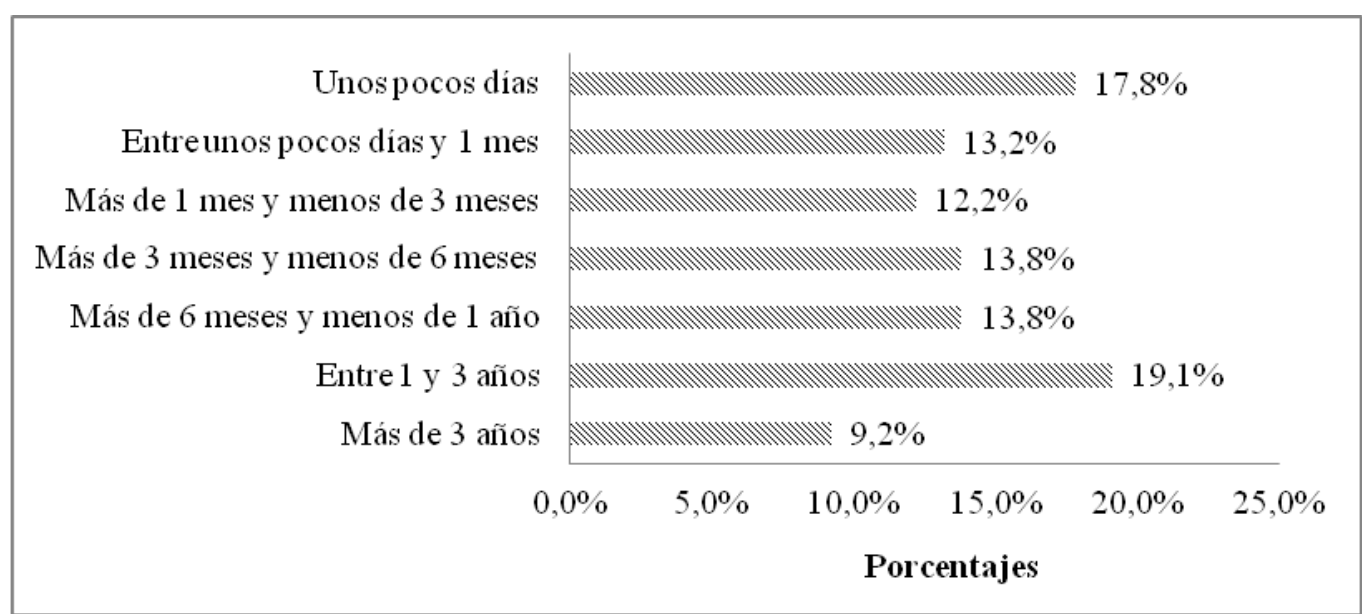

Figura 8: Duración del stalking.

Los datos aportados para las variables frecuencia y duración revelaron que a mayor duración del acoso, mayor era la frecuencia con que se experimentaban los incidentes $\left(\chi^{2}\right.$ $(12, N=152)=42.16 ; \rho<.001, \Phi=.372)$. De este modo, mientras la duración se situaba en unos pocos días, la frecuencia era de entre 2 y 5 veces por semana (81.5\%). En cambio, a medida que la duración aumentaba, también lo hacía la frecuencia, hasta el punto que cuando la situación duraba más de 3 años, la frecuencia era de 6 o más veces por semana en un $71.4 \%$ de los casos.

\section{Discusión y conclusiones}

El principal objetivo de esta investigación consistía en determinar la tasa de victimización de la población universitaria por stalking en algunas titulaciones de ciencias sociales. Los resultados derivados de la misma resultan consistentes con la literatura precedente, en el sentido de arrojar una elevada tasa de victimización en este grupo de población por este tipo de conductas (del 40\%), aunque únicamente poco más de un cuarto de las víctimas se identifiquen como tales. La incidencia de estos comportamientos en población universitaria conduce a afirmar que el stalking en este grupo de edad constituye un fenómeno claramente prevalente. Tal constatación permite apuntalar argumentaciones favorables a la conveniencia de la inclusión de un delito de stalking en el Código penal español, si bien este dato no faculta por sí solo a ir más allá, en el sentido arrojar luz para 
valorar la adecuación del tipo de conductas previsto en el delito o la gravedad de las sanciones contempladas en él.

El segundo de los objetivos de este trabajo consistía en determinar las características de la víctima. El hecho de haber efectuado una encuesta con muestra mixta y sin ligar la condición de víctima a la victimización percibida por los encuestados permite establecer las características sociodemográficas generales de las víctimas de stalking en el área geográfica en la que se ha desarrollado el estudio. Al respecto, puede indicarse que la víctima de stalking en población universitaria es un joven -mujer y también hombre-, de alrededor de 20 años, preferentemente procedente de un entorno urbano, ligado a amplios núcleos poblacionales.

La caracterización de quienes más generalizadamente se auto-identifican como víctimas es diversa. Las que se identifican como tales son mayoritariamente mujeres, procedentes de entornos de carácter más rural y que cursan estudios universitarios en cuyos currículos se contempla la formación en este tipo de procesos de victimización. En su mayoría, estas mujeres han padecido conductas que implican proximidad física del stalker.

Las divergencias existentes en la caracterización de las víctimas auto y heteroidentificadas conducen a poner en entredicho que el abordaje normativo de los comportamientos relacionados con el stalking deba producirse exclusivamente desde la perspectiva del género, concibiéndolo como una manifestación únicamente de la violencia de género. Aunque las mujeres tienen mayor facilidad que los hombres para identificarse como víctimas, la prevalencia de victimización por sexos observada (44\% en mujeres frente a $33 \%$ en hombres) no permite confirmar que nos hallamos exclusivamente frente a una manifestación de tal tipo de violencia. Así, cabe saludar que el legislador español no haya configurado el art. 172 ter CP como una expresión del Derecho penal sexuado, lo que no significa que, atendiendo a los resultados observados en este estudio, no pueda tenerse en cuenta el género de la víctima a efectos, por ejemplo, de afirmar la concurrencia del resultado típico "alterar gravemente el desarrollo de la vida cotidiana".

Cabe aventurar que sea la mayor concienciación de las mujeres frente a los hombres ante la dañosidad de este tipo de conductas la circunstancia que explique que éstas se auto-identifiquen más como víctimas que los varones, sin que pueda obviarse el 
efecto que en esta cuestión tiene el tipo de conducta padecido. No ajena a esta causa se halla la idea de que las víctimas más informadas son precisamente aquellas a quienes les resulta más fácil detectar que están pasando por el proceso de victimización, máxime si padecerlo resulta más conforme con el rol social atribuido al género al que la víctima pertenece -en este caso, el femenino-. Precisamente, la mayor conciencia sobre el fenómeno, aunque en esta ocasión únicamente deducida del mejor conocimiento de estas situaciones, permite explicar que estudiantes de titulaciones que sufren menos victimización, como seguridad privada o criminología, se identifiquen más fácilmente como víctimas.

En este sentido, resulta más complejo explicar que las víctimas de zonas urbanas sean más refractarias a la auto-identificación que las de zonas más rurales, puesto que cabría pensar que el acceso al conocimiento de contemporáneas formas de victimización se posibilita más en ciudades de medio o gran tamaño que en entornos más rurales. Sin embargo, en este caso la menor tasa de auto-identificación puede deberse a una mayor tolerancia hacia formas de victimización más sutiles -como el stalking- entre los residentes en zonas urbanas, donde existe una mayor prevalencia de formas severas de victimización.

El tercero de los objetivos de esta investigación perseguía caracterizar al ofensor. Desde la exclusiva perspectiva de quienes se auto-identifican como víctimas, generalmente el acosador es un hombre, que actúa en solitario, más cuanto más estrecha es la relación entre víctima y stalker, que generalmente forma parte del entorno más o menos íntimo de la víctima, aunque siendo las víctimas estudiantes universitarios no acostumbre a ser su cónyuge o ex cónyuge. Tampoco el hecho de que los stalkers sean mayoritariamente hombres debe conducir a ofrecer un tratamiento legal del stalking como manifestación del Derecho penal sexuado, puesto que cuando la variable sexo del ofensor se cruza con el sexo de la víctima se observa que en casos de víctima hombre la hegemonía de los stalkers de sexo masculino no resulta tan evidente.

Finalmente, el cuarto de los objetivos de esta investigación perseguía establecer la dinámica de este tipo de victimización. La conducta más común consiste en enviar correos electrónicos, mensajes de texto o instantáneos ofensivos o amenazadores, confirmando la hegemonía de las conductas de cyberstalking en el segmento poblacional analizado. Se trata en su mayoría de acosos que no superan el año de duración y que se repiten 
generalmente de 2 a 5 veces por semana. Con ser las manifestaciones del cyberstalking las más prevalentes, las víctimas tienden más a auto-identificarse como tales cuando padecen conductas en las que el stalker busca la aproximación física. Además, estas últimas conductas son percibidas por las víctimas como las más graves, siendo mayoritariamente las mujeres quienes las padecen.

Este estudio evidencia como el empleo de las tecnologías de la información y la comunicación permite explicar el amplio espectro de algunos tipos de victimización, cosa que cabría decir del cyberstalking en relación al stalking, lo mismo que se ha dicho en relación con la victimización sexual online de menores. Sin embargo, la gradación en la gravedad de las conductas padecidas que se deducen de las respuestas ofrecidas por las víctimas debería ser tenida en cuenta, entre otras cuestiones, para determinar la amplitud de la tipificación de estas conductas en el Código Penal o para modular la gravedad de la respuesta punitiva contemplada para las mismas, esto sin perder de vista que quienes mayoritariamente padecen los comportamientos más graves acostumbran a ser mujeres.

\section{Referencias}

Baum, K., Catalano, S., Rand, M., \& Rose, K. (2009). Stalking victimization in the United States. Bureau of Justice Statistics Special Report. Washington, DC: US Department of Justice.

Bjerregaard, B. (2000). An Empirical Study of Stalking Victimization. Violence and Victims, 15(4), 389-406.

Björklund, K., Häkkänen-Nyholm, H., Sheridan, L., \& Roberts, K. (2010). The Prevalence of Stalking Among Finnish University Students. Journal of Interpersonal Violence, 25(4), 684-698. doi: 10.1177/0886260509334405

Black, M. C., Basile, K. C., Breiding, M. J., Smith, S. G., Walters, M. L. Merrick, M. T., Chen, J., \& Stevens, M. R. (2011). The National Intimate Partner and Sexual Violence Survey (NISVS): 2010 Summary Report. Atlanta, GA: National Center for Injury Prevention and Control of the Centers for Disease Control and Prevention.

Budd, T., \& Mattinson, J. (2000). The extent and nature of staling: findings from the 1998 British Crime Survey. Londres: Home Office Research Study 210, Home Office Research, Development and Statistics Directorate.

Burgess, A. W., Baker, T., Greenin, D., Hartman, C. R., Burgess, A. G., Douglas, J. E., \& Halloran, R. (1997). Stalking Behaviors Within Domestic Violence. Journal of Family Violence, 12(4), 389-403. doi: 10.1023/A:1021931509143

Catalano, S. (2012). Stalking victims in the United States - Revised. Bureau of Justice Statistics Special Report. Washington, DC: US Department of Justice. 
De Fazio, L. (2011). Criminalization of stalking in Italy: One of the last among the current European member states' anti-stalking laws. Behavioral Sciences \& the Law, 29(2), 317-323. doi: 10.1002/bsl.983

Dovelius, A. M., Öberg, J., \& Holmberg, S. (2006). Stalking in Sweden-Prevalence and prevention. Estocolmo: Edita Norstedts.

Douglas, K. S., \& Dutton, D. G. (2001). Assessing the link between stalking and domestic violence. Aggression and violent behavior, 6(6), 519-546. doi: 10.1016/S13591789(00)00018-5

Feltes, T., Balloni, A., Czapska, J., Bodelón, E., \& Stenning, P. (2012). Gender-based Violence, Stalking and Fear of Crime. Research project 2009-2011. Research Report Publication. Bochum: Ruhr-Universität Bochum.

Fisher, B. S., Cullen, F. T., \& Turner, M.G. (2000). The Sexual Victimization of College Women. Washington, DC: US Department of Justice.

FRA. (2014). Violence against women: an EU-wide survey. Main Results. Luxemburgo: Publications Office of the European Union.

Freidl, W., Neuberger, I., Schönberger, W., \& Raml, R. (2011). Stalking and Health - An Austrian Prevalence Study. Gesundheitswesen, 73(4), 74-77. doi: 10.1055/s0030-1249649

Fremouw, W. J., Westrup, D., \& Pennypacker, J. (1997). Stalking on Campus: The Prevalence and Strategies for Coping with Stalking. Journal of Forensic Sciences, 42(4), 666-669.

Haugaard, J. J., \& Seri, L. G. (2003). Stalking and Other Forms of Intrusive Contact After the Dissolution of Adolescent Dating or Romantic Relationships. Violence and Victims, 18(3), 279-297.

Hoffmann, J. (2006). Stalking. Heidelberg: Springer.

Igareda, N., \& Bodelón, E. (2014). Las violencias sexuales en las universidades: cuando lo que no se denuncia no existe. Revista Española de Investigación Criminológica, 12(1), 1-27.

Istituto Nazionale di Statistica. (2007). La violenza e i maltrattamenti contro le donne dentro e fuori la familia, Anno 2006. Roma: Istat.

Logan, T. K., Leukefeld, C., \& Walker, B. (2000). Stalking as a Variant of Intimate Violence: Implication From a Young Adult Sample. Violence and Victims, 15(1), 91-111.

Matos, M., Grangeia, H., Ferreira, C., \& Azevedo, V. (2011). Inquérito de Vitimação por Stalking. Relatório de Investigação, Grupo de Investigação sobre Stalking em Portugal. Minho: Universidade do Minho.

McLennan, W. (1996). Women's safety Australia. Canberra: Australia Bureuau of Statistics.

McNamara, C. L., \& Marsil, D. F. (2012). The Prevalence of Stalking Among College Students: The Disparity Between Researcher- and Self-identified Victimization. Journal of American College Health, 60(2), 168-174. doi: $10.1080 / 07448481.2011 .584335$

Narud, K., Friestad, C., \& Dahl, A. A. (2014). Stalking experiences and associated factors - A controlled population-based study from Norway. Nord Journal of Psychiatry, 68(5), 347-354. doi: 10.3109/08039488.2013.844273

National Union of Students. (2011). A study of women students' experiences of harassment, stalking, violence and sexual assault. Londres: NUS. 
Office for National Statistics. (2015). Chapter 4: Violent Crime and Sexual Offenses Intimate Personal Violence and Serious Sexual Assault. Crime Statistics, Focus on Violent Crime and Sexual Offences, 2013/14 Release. Londres: Office for National Statistics.

Scottish Government Social Research. (2014). Scottish Crime and Justice Survey 2012/13: Sexual Victimization and Stalking. Edimburgo: Justice Analytical Services.

Steinberg, G. (2006). Nachstellen-Ein Nachruf? Juristenzeitung, 1(6), 30-33.

Tjaden, P., \& Thoennes, N. (1998). Stalking in America: Findings From the National Violence Against Women Survey. Washington, DC: US Department of Justice.

Utsch, M. (2007). Strafrechtlichle Probleme des Stalking. Berlín: Lit Verlag.

Van der Aa, S. (2010). Stalking in the Netherlands: Nature and prevalence of the problem and the effectiveness of anti-stalking measures: Tesis doctoral. Disponible en https://pure.uvt.nl/portal/en/publications/stalking-in-the-netherlands(3b936c3f0c35-4bd4-b31a-8cca2b707cd9).html

Villacampa, C. (2009). Stalking y derecho penal: relevancia jurídico-penal de una nueva forma de acoso. Madrid: Iustel.

\section{Agradecimientos}

Agradecemos a nuestros compañeros universitarios profesores de Derecho penal y Criminología en las universidades donde se ha llevado a cabo la recogida de datos su disponibilidad y su valiosa colaboración.

\section{Financiación}

Este trabajo ha sido financiado con cargo al proyecto "Formas contemporáneas de violencia de género: mecanismos jurídicos de protección de las víctimas" (I+D DER2015-64506-C2-1-R).

Carolina Villacampa es Catedrática acr. Derecho Penal de la Universitat de Lleida. Dirige el Máster Oficial Interuniversitario en Sistema de Justicia Penal y es miembro del Grupo de Investigación en Sistema de Justicia Penal. En los últimos años sus principales líneas de investigación se han centrado en el análisis de los derechos de las víctimas y de concretos ámbitos de la victimización, entre ellos el stalking.

Alejandra Pujols es becaria FI de Derecho Penal de la Universitat de Lleida y miembro del Grupo de Investigación en Sistema de Justicia Penal. Actualmente se halla realizando su tesis doctoral, que versa sobre los aspectos fenomenológicos y jurídicos del stalking. 